\title{
Questionnaire Breakoff and Item Nonresponse in Web-Based Questionnaires: Multilevel Analysis of Person-Level and Item Design Factors in a Birth Cohort
}

Cauane Blumenberg ${ }^{1^{*}}, \mathrm{MSc}$; Daniela Zugna ${ }^{2^{*}}, \mathrm{PhD} ;$ Maja Popovic $^{2^{*}}, \mathrm{MSc}$; Costanza Pizzi ${ }^{2^{*}}, \mathrm{PhD}$; Aluisio J D Barros ${ }^{1^{*}}$, $\mathrm{PhD}$; Lorenzo Richiardi ${ }^{2 *}, \mathrm{PhD}$

\footnotetext{
${ }^{1}$ Center for Epidemiological Research, Post-Graduate Program in Epidemiology, Federal University of Pelotas, Pelotas, Brazil

${ }^{2}$ Cancer Epidemiology Unit, Department of Medical Sciences, University of Turin, Turin, Italy

*all authors contributed equally
}

\section{Corresponding Author:}

Cauane Blumenberg, MSc

Center for Epidemiological Research

Post-Graduate Program in Epidemiology

Federal University of Pelotas

1160 Marechal Deodoro Street, 3rd Floor

Pelotas, 96020-220

Brazil

Phone: 555332841300

Fax: 555332841300

Email: cauane.epi@gmail.com

\section{Abstract}

Background: Web-based questionnaires are increasingly used in epidemiologic studies, as traditional methods are facing a decrease in response rates and an increase in costs. However, few studies have investigated factors related to the level of completion of internet-based epidemiologic questionnaires.

Objective: Our objective was to identify person-level characteristics and item design factors associated with breakoff (not finishing the questionnaire) and item nonresponse in a Web-based questionnaire.

Methods: This study was a cross-sectional analysis of the baseline questionnaire, applied from 2005 to 2016 , of the Italian NINFEA (Nascita e Infanzia: gli Effetti dell'Ambiente) birth cohort. The baseline questionnaire was administered to enrolled women, who could register at any time during pregnancy. We used logistic regression to analyze the influence of person-level factors on questionnaire breakoff, and a logistic multilevel model (first level: items of the questionnaire; second level: sections of the questionnaire; third level: study participants) to analyze the influence of person-level and item design factors on item nonresponse. Since the number of applicable items depended on the respondent's characteristics and breakoff, we used inverse probability weighting to deal with missing by design.

Results: Of 5970 women, 519 (8.69\%) did not finish the questionnaire. Older age (adjusted odds ratio 1.40, 95\% CI 1.05-1.88), lower educational level (adjusted odds ratio [OR] 1.53, 95\% CI 1.23-1.90), and earlier stage of pregnancy (adjusted OR 3.01, 95\% CI 2.31-3.92) were positively associated with questionnaire breakoff. Of the 1,062,519 applicable items displayed for the participants, 22,831 were not responded to (overall prevalence of item nonresponse $2.15 \%$ ). Item nonresponse was positively associated with older age (adjusted OR 1.25, 95\% CI 1.14-1.38), being in the first trimester of pregnancy (adjusted OR 1.18, 95\% CI 1.06-1.31), and lower educational level (adjusted OR 1.23, 95\% CI 1.14-1.33). Dropdown menu items (adjusted OR 1.77, 95\% CI 1.56-2.00) and items organized in grids (adjusted OR 1.69, 95\% CI 1.49-1.91) were positively associated with item nonresponse.

Conclusions: It is important to use targeted strategies to keep participants motivated to respond. Item nonresponse in internet-based questionnaires is affected by person-level and item design factors. Some item types should be limited to reduce item nonresponse.

(J Med Internet Res 2018;20(12):e11046) doi: 10.2196/11046 


\section{KEYWORDS}

epidemiology; internet; surveys and questionnaires; epidemiologic research design; data collection

\section{Introduction}

\section{Background}

Novel data collection methods are increasingly used in epidemiologic studies [1,2], as traditional methods, including mail questionnaires, face-to-face interviews, and telephone interviews, are facing a decrease in response rates [3] and an increase in costs [4]. Given the limitations of traditional methods and the growing internet penetration, the number of Web-based e-epidemiologic studies is increasing worldwide [1].

Compared with traditional methods, Web-based epidemiologic questionnaires have clear advantages, such as higher data quality (if filtering questions and consistency checks are used) and lower costs [1]. However, they may also have weaknesses that should be explored empirically [5]. In particular, the validity of epidemiologic studies may be jeopardized by lower response rates [6], questionnaire breakoff (not finishing the questionnaire), and item nonresponse [7], which can depend on participants' characteristics and item design factors [8,9]. For instance, in a study investigating homosexual rights, the item nonresponse rates were higher among heterosexual individuals than among homosexual individuals [10]. In this case, the item nonresponse rates varied according to individual characteristics that were relevant to the objectives of the study, and this could bias the results [11].

\section{Objective}

Although item nonresponse may have a great impact on study validity, few studies have investigated factors related to the level of completion of internet-based epidemiologic questionnaires $[12,13]$. Thus, in the context of the internet-based NINFEA (Nascita e Infanzia: gli Effetti dell'Ambiente) birth cohort study [14], we aimed at investigating the associations of person-level characteristics and item design factors with item nonresponse rate, as well as the associations of person-level characteristics with questionnaire breakoff.

\section{Methods}

\section{Participants and Baseline Questionnaire}

NINFEA is a Web-based birth cohort study, which started in Italy in 2005 [14]. Members of the cohort are children born to women who (1) had enough knowledge of the Italian language to complete internet-based questionnaires, (2) knew about the study, and (3) had access to the internet at the time of recruitment. Participants were recruited online through hyperlinks leading to the NINFEA website that were displayed on selected hospitals' home pages, pregnancy-related websites, and the NINFEA Facebook page, and offline using leaflets, face-to-face contacts, and posters placed in selected hospitals and clinics. The study was also advertised in local and national media in Italy. All selected hospitals and clinics for online and offline recruitment were located in the Piedmont and Tuscany regions, from which $82.87 \%(6391 / 7712)$ of the cohort originated. Pregnant women could enroll by registering at the study website [15] at any time during pregnancy. The ethical committees of the San Giovanni Battista Hospital and the Orthopedic Traumatology Center, Functional Re-education Center, Maria Adelaide Hospital, Turin, Italy (approval \#0048362 and following amendments) approved the study, and all participants consented to participate. At enrollment, they completed a baseline questionnaire, and then were invited to fill in 5 follow-up questionnaires when their child turned 6 months, 18 months, 4 years, 7 years, and 10 years of age. This study focused on the baseline questionnaire.

In the period from 2005 to 2016 , a total of 7712 pregnant women completed the NINFEA baseline questionnaire (database version 03.2017), and 1176 women participated during more than 1 pregnancy. The questionnaire was initially developed using the Hypertext Preprocessor scripting language [16]. After the first 1500 respondents, a major review of the questions was done and an updated version of the questionnaire was implemented using the Ruby programming language [17]. To avoid comparability issues, for this study we considered only the 5970 pregnant women who completed at least one section of the Ruby version.

The baseline questionnaire is composed of 18 sections investigating demographic factors, maternal general health, exposures before and during pregnancy, lifestyle, and reproductive history. Of these sections, 4 are supplementary and entirely dependent on answers given in the preceding section, and thus we did not consider them in the analyses. In total we included 244 items in the 14 analyzed sections; of these, 7 items were mandatory and therefore we excluded them from the analyses. We thus analyzed a total of 237 items, although the actual number of items presented to each participant at the time they completed the questionnaire varied due to filter questions that render sets of questions not applicable. For example, a negative answer to the filter question "Did you smoke during pregnancy?" would skip a series of questions about smoking. In contrast, a positive answer to the same filter question would present a set of applicable questions about smoking to the respondent.

\section{Questionnaire Breakoff and Item Nonresponse}

We analyzed 2 outcomes: questionnaire breakoff and item nonresponse. We considered a respondent to have broken off the questionnaire if she stopped answering the items before reaching the last section. If the last section was fully or partially completed and submitted, we considered the questionnaire not to be broken off, even if some items were left blank in the preceding sections. For this reason, no breakoff could have occurred in the last section of the questionnaire. For the analysis of questionnaire breakoff, the units of analysis were the 5970 women who completed at least one section of the questionnaire.

We based the analyses of item nonresponse on the 237 nonmandatory items from the 14 sections of the questionnaire. We assessed each of the 237 nonmandatory items, for each of the 5970 participants, and considered a blank as a nonresponse if the item was applicable. Item nonresponse was constructed 
as a binary variable: $1=$ nonresponse, and $0=$ response. The units of analysis were the items of the questionnaire (at most 237 items $\times 5970$ women $=1,414,890$ items $)$.

We analyzed the following person-level characteristics as predictors of questionnaire breakoff: age ( $\leq 30$ years, $31-35$ years, $\geq 36$ years), university degree (yes, no), gestational trimester at enrollment (first trimester, second trimester, third trimester), first pregnancy (yes, no), employment status at the beginning of the pregnancy (employed, unemployed), type of recruitment (offline, online), Italian region of residence (Piedmont Region, Tuscany Region, other regions of Northern Italy, and other), and number of participations in the baseline questionnaire $(1, \geq 2)$. All the exposure variables were self-reported in the baseline questionnaire, except for the number of participations, which was constructed based on the total number of baseline questionnaires compiled by a woman. We assessed the type of recruitment from the first question, which asked about the way the participant had become aware of the study. We considered leaflets, posters, word-of-mouth, face-to-face invitation, and traditional media as offline recruitment methods, while we considered built-in links in websites and social media sites as online recruitment methods. Specifically, for the online recruitment, we advertised the study in selected forums or websites targeting pregnant women or health care workers, on the home pages of selected obstetric or pediatric hospitals or hospitals with a large number of deliveries, and on the NINFEA Facebook page. The number of involved websites, forums, and hospitals changed over time depending on the specific type of collaboration that was initiated. We conducted two small Facebook campaigns with advertisements targeting women in fertile age [18].

We assessed item nonresponse in association with the person-level characteristics analyzed for questionnaire breakoff, as well as in association with the design of the items themselves: (1) item type (checkbox, dropdown menu, radio button, text), (2) number of response options, and (3) whether the item was located in a grid (yes, no). Multimedia Appendix 1 provides examples of the item design characteristics. Specifically, radio button items can have only 1 answer selected among a set of predefined response options; dropdown menu items also have only 1 possible answer, but the list of response options is collapsed by default and has to be actively expanded to read the possible responses; checkboxes accept the selection of more than 1 answer from a set of predefined response options; and text items require the insertion of numeric or textual content. Some items in the questionnaire combined a radio button or a checkbox with a text item (eg, items with response options "Other, namely..."); these were considered as 2 individual items. We categorized the number of response options as 2, 3 to 5, and at least 6 options; we did not consider text items because they do not have any response option. An item was considered to be located in a grid if it was part of a group of items that shared the same set of response options and that required the respondents to link rows and columns in order to select an appropriate answer.

\section{Statistical Analyses}

We estimated the odds ratios (ORs) and 95\% confidence intervals of breaking off the questionnaire according to person-level factors by using logistic regression with robust variance estimation to account for the correlation between the responses of mother who participated in the NINFEA cohort during more than 1 pregnancy.

To analyze the association of person-level and item design factors with item nonresponse, we used a 3-level hierarchical logistic regression model. The questionnaire items composed the first level, the questionnaire sections were the second level, and the women responding to the questionnaire were the third level. We fitted crude and adjusted models, by adjusting mutually for maternal age, university degree, employment status, gestational trimester, whether it was a first pregnancy, type of recruitment, region of residence, and number of participations.

As filters were used in the questionnaire, the total number of items to be responded to varied among participants. To account for these differences, we applied the inverse probability weighting (IPW) technique to deal with data missing by design [19]. In this study, we calculated the weights as the inverse of the probability of having a missing datum (by design) on every dependent item by considering only the women for whom that item was applicable. We estimated the weights using a logistic regression model that included the following person-level characteristics: age, university degree, gestational trimester at enrollment, whether it was a first pregnancy, employment status at the beginning of the pregnancy, and the type of recruitment. The underlying idea of IPW is to create weighted copies of the complete cases (dependent applicable items), according to selected person-level characteristics, to remove the selection bias introduced by the missing data. By doing so, we assumed that the nonresponse probability of women for whom the item was not applicable was equal to the nonresponse probability of women for whom the item was applicable, given that they had the same selected person-level characteristics. We did not truncate high-weight values, as, in sensitivity analyses, truncation at the 95th or 99th percentile did not affect the results more than marginally.

Analyses were conducted using the Stata 15.0 software (StataCorp LLC).

\section{Results}

\section{Participant Characteristics}

Table 1 lists the main characteristics of the 5970 women included in the analyses. Most of the NINFEA participants lived in the Piedmont Region, were recruited offline, and were in the third trimester of pregnancy. Two-thirds of women were younger than 35 years $(n=4235)$, and more than half had a university degree $(n=3605)$, were employed $(n=5067)$, or were in their first pregnancy $(n=3196)$. A total of 1176 women participated with more than 1 pregnancy in the NINFEA birth cohort. 
Table 1. Characteristics of the study population $(\mathrm{N}=5970)$.

\begin{tabular}{|c|c|}
\hline Participant characteristics & $\mathrm{n}(\%)^{\mathrm{a}}$ \\
\hline \multicolumn{2}{|l|}{ Age group (years) } \\
\hline$\leq 30$ & $1735(29.06)$ \\
\hline $31-35$ & $2505(41.96)$ \\
\hline$\geq 36$ & $1730(28.98)$ \\
\hline \multicolumn{2}{|l|}{ University degree } \\
\hline Yes & $3605(61.59)$ \\
\hline No & $2248(38.41)$ \\
\hline \multicolumn{2}{|l|}{ Employment status } \\
\hline Unemployed & $903(15.13)$ \\
\hline Employed & $5067(84.87)$ \\
\hline \multicolumn{2}{|l|}{ Gestational trimester } \\
\hline First & $968(16.41)$ \\
\hline Second & $1798(30.48)$ \\
\hline Third & $3133(53.11)$ \\
\hline \multicolumn{2}{|l|}{ First pregnancy } \\
\hline Yes & $3196(53.58)$ \\
\hline No & $2769(46.42)$ \\
\hline \multicolumn{2}{|l|}{ Type of recruitment } \\
\hline Offline & $4839(83.71)$ \\
\hline Online & $942(16.29)$ \\
\hline \multicolumn{2}{|l|}{ Region of residence } \\
\hline Piedmont Region & $3328(56.14)$ \\
\hline Tuscany Region & $1720(29.01)$ \\
\hline Other regions of North Italy & $500(8.43)$ \\
\hline Other & $380(6.41)$ \\
\hline \multicolumn{2}{|l|}{ Number of participations } \\
\hline 1 & $4794(80.30)$ \\
\hline$\geq 2$ & $1176(19.70)$ \\
\hline
\end{tabular}

${ }^{\mathrm{a}}$ Total numbers may vary due to missing values.

\section{Questionnaire Breakoff and Item Nonresponse Characteristics}

Table 2 shows the number of sections, item characteristics, and nonresponse percentage according to item design characteristics. We analyzed a total of 237 items from 14 sections in this study. Almost half of the items $(n=116)$ were radio button type and included 3 to 5 response options. Of the 237 items, 39 (16.5\%) were located in a grid. The highest nonresponse percentages among the applicable items were observed for filter questions, dropdown menu items, items containing 3 to 5 response options, and items located in grids.
Of the 5970 women, $519(8.69 \%)$ did not finish the NINFEA baseline questionnaire. Breakoffs were spread over the 13 sections of the questionnaire. Table 3 shows the ORs of breakoff depending on the participants' characteristics. Women who at enrollment were in the first trimester of pregnancy had a threefold higher odds of questionnaire breakoff than did those who were in the third trimester of pregnancy (adjusted OR 3.01, 95\% CI 2.31-3.92). Women without a university degree had $53 \%$ higher odds of questionnaire breakoff (95\% CI 1.23-1.90) than did those with a higher education. Older age was also positively associated with questionnaire breakoff. 
Table 2. Characteristics of the questionnaire items and frequency of nonresponse according to item characteristics.

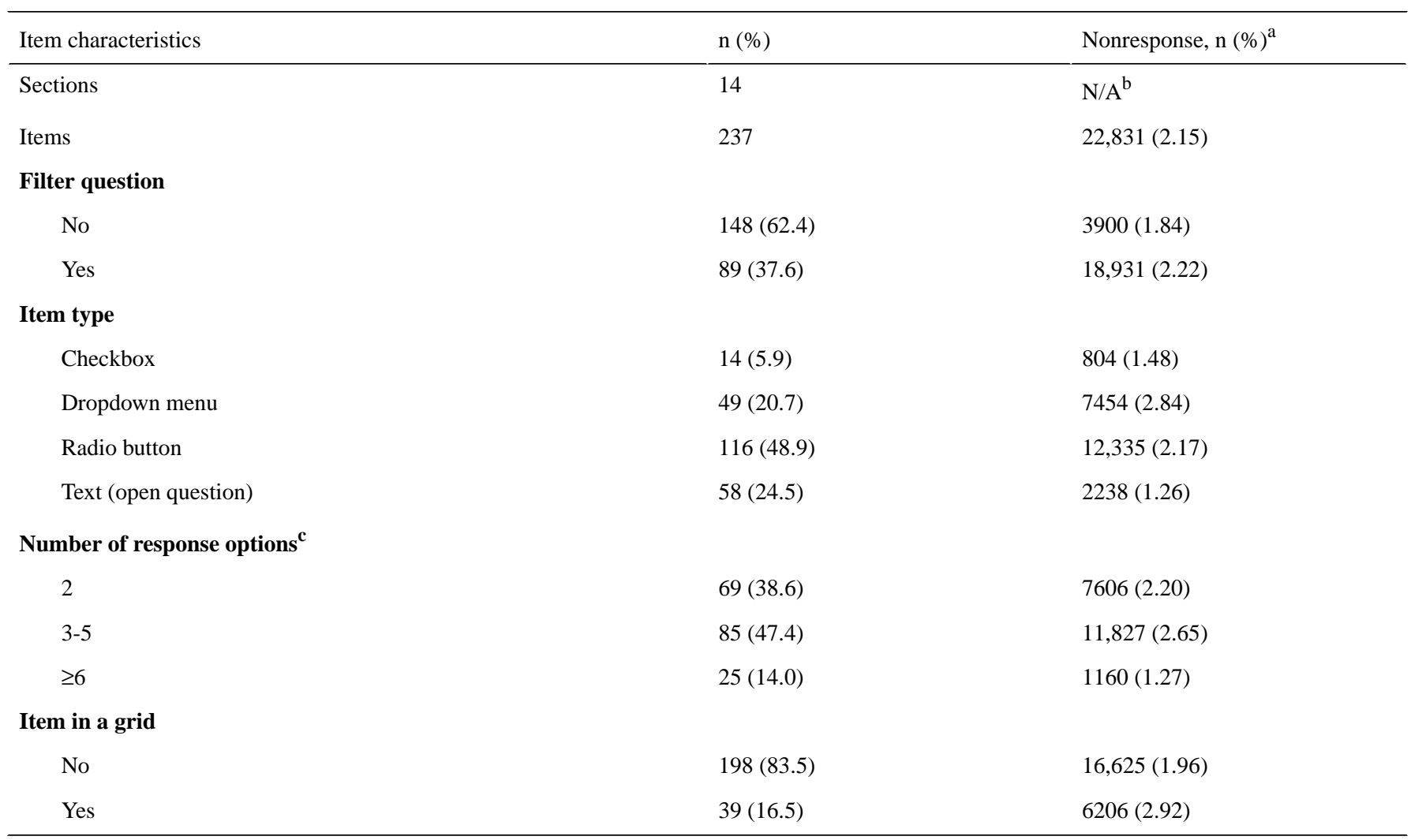

${ }^{\mathrm{a}}$ Calculated as the ratio between the total number of items not responded to and the total number of applicable items $(\mathrm{n}=1,062,519)$ for all participants. ${ }^{\mathrm{b}} \mathrm{N} / \mathrm{A}$ : not applicable.

${ }^{\mathrm{c}}$ Text items were not considered. 
Table 3. Questionnaire breakoff according to participants' characteristics.

\begin{tabular}{|c|c|c|c|}
\hline Participant characteristics & $\mathrm{n}(\%)$ & Crude analyses, $\mathrm{OR}^{\mathrm{a}}(95 \% \mathrm{CI})$ & Adjusted analyses $^{\mathrm{b}}, \mathrm{OR}(95 \% \mathrm{CI})$ \\
\hline \multicolumn{4}{|l|}{ Age group (years) } \\
\hline$\leq 30$ & $137(7.9)$ & 1.00 & 1.00 \\
\hline $31-35$ & $213(8.5)$ & $1.08(0.87-1.36)$ & $1.11(0.84-1.44)$ \\
\hline$\geq 36$ & $169(9.8)$ & $1.26(1.00-1.60)$ & $1.40(1.05-1.88)$ \\
\hline \multicolumn{4}{|l|}{ University degree } \\
\hline Yes & $220(6.1)$ & 1.00 & 1.00 \\
\hline No & $206(9.2)$ & $1.55(1.27-1.90)$ & $1.53(1.23-1.90)$ \\
\hline \multicolumn{4}{|l|}{ Employment status } \\
\hline Employed & $363(7.2)$ & 1.00 & 1.00 \\
\hline Unemployed & $156(17.3)$ & $2.71(2.21-3.32)$ & $0.99(0.73-1.34)$ \\
\hline \multicolumn{4}{|l|}{ Gestational trimester } \\
\hline Third & $189(6.0)$ & 1.00 & 1.00 \\
\hline Second & $134(7.5)$ & $1.25(1.00-1.58)$ & $1.27(0.98-1.65)$ \\
\hline First & $170(17.6)$ & $3.32(2.65-4.15)$ & $3.01(2.31-3.92)$ \\
\hline \multicolumn{4}{|l|}{ First pregnancy } \\
\hline Yes & $233(7.3)$ & 1.00 & 1.00 \\
\hline No & $286(10.3)$ & $1.47(1.22-1.76)$ & $1.13(0.90-1.43)$ \\
\hline \multicolumn{4}{|l|}{ Type of recruitment } \\
\hline Offline & $389(8.0)$ & 1.00 & 1.00 \\
\hline Online & $107(11.4)$ & $1.47(1.17-1.84)$ & $1.11(0.82-1.51)$ \\
\hline \multicolumn{4}{|l|}{ Region of residence } \\
\hline Piedmont Region & $236(7.1)$ & 1.00 & 1.00 \\
\hline Tuscany Region & $170(9.9)$ & $1.44(1.17-1.77)$ & $1.06(0.84-1.35)$ \\
\hline Other regions of North Italy & $49(9.8)$ & $1.42(1.03-1.97)$ & $1.14(0.75-1.73)$ \\
\hline Other & $54(14.2)$ & $2.17(1.58-2.99)$ & $1.80(1.21-2.66)$ \\
\hline \multicolumn{4}{|l|}{ Number of participations } \\
\hline 1 & $387(8.1)$ & 1.00 & 1.00 \\
\hline$\geq 2$ & $132(11.2)$ & $1.44(1.17-1.77)$ & $1.19(0.91-1.57)$ \\
\hline
\end{tabular}

${ }^{\mathrm{a}} \mathrm{OR}$ : odds ratio.

${ }^{\mathrm{b}}$ Models adjusted for age, university degree, employment status, gestational trimester, first pregnancy, type of recruitment, region, and number of participations.

Of the 1,062,519 applicable items, 22,831 were not responded to, giving an overall item nonresponse rate of $2.15 \%$. Table 4 presents the weighted crude and adjusted ORs of item nonresponse according to participants' characteristics. Similar to the findings for questionnaire breakoff, lower educational level, older age, and enrollment in the first trimester of pregnancy were positively associated with item nonresponse. In contrast, participating during 2 or more pregnancies (ie, responding to the questionnaires twice or more often) was associated with lower odds of item nonresponse. Number of pregnancies, employment status, and type of recruitment were not associated with item nonresponse in our study.
All the analyzed item design factors were associated with item nonresponse (Table 5). Items designed as a dropdown menu were $77 \%$ more likely to be left blank than were radio button items (95\% CI 1.56-2.00). Text items had 30\% lower odds of item nonresponse (95\% CI 0.63-0.79) and checkboxes had $80 \%$ lower odds of item nonresponse (95\% CI 0.16-0.25) than did radio button items. Items with 6 or more response options were $59 \%$ less likely to be left blank than were those with 2 response options (95\% CI 0.35-0.47). Finally, items being located in a grid was positively associated with nonresponse (adjusted OR $1.69,95 \%$ CI $1.49-1.91)$. 
Table 4. Prevalence and crude and adjusted odds ratios (ORs) of item nonresponse according to participants' characteristics.

\begin{tabular}{|c|c|c|c|}
\hline Participant characteristics & Prevalence $(\%)$ & Crude analyses, OR $(95 \% \mathrm{CI})$ & Adjusted analyses $^{\mathrm{a}}$, OR (95\% CI) \\
\hline \multicolumn{4}{|l|}{ Age group (years) } \\
\hline$\leq 30$ & 2.1 & 1.00 & 1.00 \\
\hline $31-35$ & 2.0 & $1.03(0.95-1.13)$ & $1.07(0.98-1.17)$ \\
\hline$\geq 36$ & 2.4 & $1.25(1.14-1.38)$ & $1.25(1.14-1.38)$ \\
\hline \multicolumn{4}{|l|}{ University degree } \\
\hline Yes & 1.9 & 1.00 & 1.00 \\
\hline No & 2.4 & $1.22(1.14-1.31)$ & $1.23(1.14-1.33)$ \\
\hline \multicolumn{4}{|l|}{ Employment status } \\
\hline Employed & 2.0 & 1.00 & 1.00 \\
\hline Unemployed & 3.0 & $0.89(0.78-1.01)$ & $0.87(0.77-0.98)$ \\
\hline \multicolumn{4}{|l|}{ Gestational trimester } \\
\hline Third & 2.0 & 1.00 & 1.00 \\
\hline Second & 2.1 & $1.04(0.96-1.12)$ & $1.00(0.93-1.09)$ \\
\hline First & 2.6 & $1.17(1.06-1.29)$ & $1.18(1.06-1.31)$ \\
\hline \multicolumn{4}{|l|}{ First pregnancy } \\
\hline Yes & 2.2 & 1.00 & 1.00 \\
\hline No & 2.1 & $1.05(0.98-1.12)$ & $1.03(0.95-1.11)$ \\
\hline \multicolumn{4}{|l|}{ Type of recruitment } \\
\hline Offline & 2.1 & 1.00 & 1.00 \\
\hline Online & 2.4 & $1.12(1.01-1.23)$ & $1.07(0.96-1.18)$ \\
\hline \multicolumn{4}{|l|}{ Region of residence } \\
\hline Piedmont Region & 1.9 & 1.00 & 1.00 \\
\hline Tuscany Region & 2.5 & $1.17(1.08-1.27)$ & $1.16(1.07-1.25)$ \\
\hline Other regions of North Italy & 1.9 & $1.02(0.90-1.15)$ & $0.97(0.85-1.11)$ \\
\hline Other & 2.8 & $1.37(1.16-1.61)$ & $1.14(0.98-1.34)$ \\
\hline \multicolumn{4}{|l|}{ Number of participations } \\
\hline 1 & 2.2 & 1.00 & 1.00 \\
\hline$\geq 2$ & 1.9 & $0.84(0.77-0.92)$ & $0.90(0.82-0.99)$ \\
\hline
\end{tabular}

${ }^{\mathrm{a}}$ Models adjusted for age, university degree, employment status, gestational trimester, first pregnancy, type of recruitment, region, and number of participations. 
Table 5. Crude and adjusted odds ratios (ORs) of item nonresponse according to item design factors.

\begin{tabular}{|c|c|c|}
\hline Item design factors & Crude analyses, OR $(95 \% \mathrm{CI})$ & Adjusted analyses $^{\mathrm{a}}$, OR $(95 \% \mathrm{CI})$ \\
\hline \multicolumn{3}{|l|}{ Item type } \\
\hline Radio button & 1.00 & 1.00 \\
\hline Checkbox & $0.20(0.17-0.25)$ & $0.20(0.16-0.25)$ \\
\hline Dropdown menu & $1.73(1.53-1.94)$ & $1.77(1.56-2.00)$ \\
\hline Text (open question) & $0.70(0.63-0.78)$ & $0.70(0.63-0.79)$ \\
\hline \multicolumn{3}{|l|}{ Response options } \\
\hline 2 & 1.00 & 1.00 \\
\hline $3-5$ & $1.12(1.04-1.21)$ & $1.09(1.01-1.18)$ \\
\hline$\geq 6$ & $0.41(0.35-0.47)$ & $0.41(0.35-0.47)$ \\
\hline \multicolumn{3}{|l|}{ Item in a grid } \\
\hline No & 1.00 & 1.00 \\
\hline Yes & $1.63(1.44-1.83)$ & $1.69(1.49-1.91)$ \\
\hline
\end{tabular}

${ }^{a}$ Models adjusted for age, university degree, employment status, gestational trimester, first pregnancy, type of recruitment, region, and number of participations.

\section{Discussion}

\section{Principal Findings}

Our results showed that women enrolled in earlier stages of pregnancy had a higher probability of questionnaire breakoff than did women enrolled in the third trimester of pregnancy. Older and less-educated women were more likely to break off the questionnaire and to leave items blank. Dropdown menu items were associated with the lowest response rate among all types of items. Unexpectedly, text items were less likely to be left blank than were radio button items; similarly, items with 6 or more response options were less likely to be left blank than were those with 2 response options.

Our findings of higher breakoff and item nonresponse rates among women in the first trimester of pregnancy than among those enrolled in the third trimester could be explained by several factors, including participants' time available to answer the questionnaire. Women in later stages of pregnancy might have more time to complete the questionnaire, as they are already on maternity leave. Lower educational level was positively associated with questionnaire breakoff in the NINFEA Web-based cohort. This finding is consistent with other studies that included different populations (eg, men) [20,21] or used different data collection methods, such as postal questionnaires [22]. These consistencies are of particular interest, as the NINFEA study population includes self-selected volunteers having access to the internet; nevertheless, differences in completion of the questionnaire by educational level persist. Thus, regardless of the population or data collection method, epidemiologic studies that rely on self-administered questionnaires should identify incentives to motivate participation, specifically of individuals with low educational levels.

In contrast, there are determinants that are closely related to Web-based studies, such as whether the participants became aware of the study through online or offline channels. Few studies have investigated the associations between the type of recruitment and breakoff from internet-based questionnaires [23]. Our finding of no association is in line with the findings of an internet-based intervention that found no difference in questionnaire breakoff between online and offline recruitment methods [24].

The proportion of item nonresponse was low in our study, ranging from $1.3 \%$ to $2.9 \%$. Another study that administered daily Web-based questionnaires also described low rates of item nonresponse, ranging from $0 \%$ to $7.4 \%$ [25]. In our study, online recruitment, older age, and lower educational levels were positively associated with item nonresponse. This is in line with findings of 3 quality-of-life Web-based surveys conducted in the United States [26]. The association between older age and lower educational levels with higher rates of item nonresponse is also consistent with other prior work [27,28]. Regardless of the data collection method used, these individuals have to expend a higher cognitive effort to respond to questions. In the case of a self-reported questionnaire responded to over the internet (with no support from an interviewer), the rates of nonresponse for these individuals can be even higher.

The number of times a woman participated in the NINFEA baseline questionnaire was not associated with breakoff, but it was associated with lower rates of item nonresponse. However, the confidence interval almost included the unit, and for this reason we believe this association might be due to residual confounding.

To analyze item nonresponse according to the type of item, we compared all items with the radio button items, since this was the most prevalent item in the NINFEA questionnaire. Our finding that checkbox items were associated with a lower item nonresponse than the radio button items is consistent with the literature and inherent in the logic of checkboxes [26,29]. The probability of checking at least 1 answer among several response options is likely higher than checking 1 answer among a pair 
of response options [29]. Our finding of lower item nonresponse among items with 6 or more response options than among items with 2 response options supports this hypothesis. Text items were associated with a higher response than were radio button items in our study. The association of text items with item nonresponse is still controversial in the literature, as studies found text items to be positively or negatively associated with item nonresponse [26,30]. Dropdown menu items were positively associated with item nonresponse, as they require more actions to select an answer (3 actions for dropdown menu items vs 1 action for radio button items), and this can explain the higher item nonresponse rate $[11,31]$.

As expected, items located in grids had higher odds of item nonresponse than did single items. Linking rows and columns of a grid to select an appropriate answer is more complex than choosing an answer of a single item; hence, if possible, grid items should be avoided [32,33].

Besides the design of the items, their content could also influence item nonresponse [26]. For instance, items asking about sensitive subjects could have higher nonresponse than items with nonsensitive content [34]. However, we did not perceive this behavior in our study. In the NINFEA baseline questionnaire, we considered only 3 of the 237 items to have sensitive content: alcohol consumption during pregnancy, use of soft drugs during pregnancy, and smoking during pregnancy. There were no missing responses for the first 2 items and 9 missing responses for the item asking about smoking.

\section{Conclusion}

We obtained our findings within the context of a longitudinal epidemiologic study: the NINFEA Web-based birth cohort. In this type of study, it is very important to avoid breakoffs and item nonresponse, since the presence of missing values in the baseline questionnaires makes analyses of future outcomes difficult. Using the IPW technique and multilevel modeling, we were able to comprehensively and concurrently analyze the association of person-level and item design factors with item nonresponse. By doing so, we were also able to adjust all analyses for the characteristics of the mothers.

To our knowledge, this is the first study evaluating determinants of questionnaire breakoff and item nonresponse in the context of e-epidemiology. Our study was based on only 1 internet-based epidemiologic study and included only pregnant women; thus, replications in other populations and settings are needed. It is crucial to understand the profile of nonresponders to develop personalized motivation methods and minimize item nonresponse and breakoffs. Personalized recruitment [35,36], use of reminders [37,38], incentives [39,40], and gamification [41] are only some of the strategies that can be used to keep participants motivated.

The low percentage of breakoffs in the baseline questionnaire of the NINFEA birth cohort demonstrates the feasibility of e-epidemiologic research, even when long questionnaires are applied. However, the questionnaires should be designed carefully. For instance, items with 1 and several radio button options should replace dropdown menu items and items located in grids, respectively, in order to reduce nonresponse. Also, we showed several person-level characteristics to be important determinants of breakoff and item nonresponse in internet-based questionnaires. For this reason, study coordinators should know their target population so as to employ focused motivation and recruitment techniques and to reduce breakoff and item nonresponse. Older and less educated individuals should be contacted directly (even by other means, such as telephone) in order to assist and encourage their participation in e-epidemiologic research.

\section{Acknowledgments}

This work was conducted during a PhD exchange period at the University of Turin, Italy, sponsored by the Capes Foundation within the Ministry of Education, Brazil (grant \#88881.133234/2016-01).

\section{Conflicts of Interest}

None declared.

\section{Multimedia Appendix 1}

Examples of item characteristics.

[PDF File (Adobe PDF File), 68KB-Multimedia Appendix 1]

\section{References}

1. Ekman A, Litton J. New times, new needs; e-epidemiology. Eur J Epidemiol 2007;22(5):285-292. [doi: 10.1007/s10654-007-9119-0] [Medline: 17505896 ]

2. van Gelder MM, Bretveld RW, Roeleveld N. Web-based questionnaires: the future in epidemiology? Am J Epidemiol 2010 Dec 1;172(11):1292-1298 [FREE Full text] [doi: 10.1093/aje/kwq291] [Medline: 20880962]

3. Morton LM, Cahill J, Hartge P. Reporting participation in epidemiologic studies: a survey of practice. Am J Epidemiol 2006 Feb 01;163(3):197-203. [doi: 10.1093/aje/kwj036] [Medline: 16339049]

4. Sinclair M, O'Toole J, Malawaraarachchi M, Leder K. Comparison of response rates and cost-effectiveness for a community-based survey: postal, internet and telephone modes with generic or personalised recruitment approaches. BMC Med Res Methodol 2012;12:132 [FREE Full text] [doi: 10.1186/1471-2288-12-132] [Medline: 22938205] 
5. van Gelder MM, Pijpe A. E-epidemiology: a comprehensive update. OA Epidemiol 2013 Jun 04;1(1). [doi: 10.13172/2053-079X--1-584]

6. Blumenberg C, Barros AJD. Response rate differences between web and alternative data collection methods for public health research: a systematic review of the literature. Int J Public Health 2018 Jul;63(6):765-773. [doi:

10.1007/s00038-018-1108-4] [Medline: 29691594]

7. Groves R, Dillman DA, Little RJA, Eltinge JL. Survey Nonresponse. New York, NY: John Wiley \& Sons; 2001.

8. Peytchev A. Survey breakoff. Public Opin Q 2009 Apr 02;73(1):74-97. [doi: 10.1093/poq/nfp014]

9. Phillips AW, Reddy S, Durning SJ. Improving response rates and evaluating nonresponse bias in surveys: AMEE guide no. 102. Med Teach 2016 Dec;38(3):217-228. [doi: 10.3109/0142159X.2015.1105945] [Medline: 26648511]

10. Liu M, Wang Y. Comparison of face-to-face and web surveys on the topic of homosexual rights. J Homosex 2016 Jun;63(6):838-854. [doi: 10.1080/00918369.2015.1112587] [Medline: 26566766]

11. Dillman DA, Smyth JD, Christian LM. Internet, Phone, Mail, and Mixed-Mode Surveys: The Tailored Design Method. Hoboken, NJ: John Wiley \& Sons; 2014.

12. Steinbrecher M, Rossmann J, Blumenstiel J. Why do respondents break off web surveys and does it matter? Results from four follow-up surveys. Int J Public Opin Res 2014 Sep 09;27(2):289-302. [doi: 10.1093/ijpor/edu025]

13. Rothman KJ, Mikkelsen EM, Riis A, Sørensen HT, Wise LA, Hatch EE. Randomized trial of questionnaire length. Epidemiology 2009 Jan;20(1):154. [doi: 10.1097/EDE.0b013e31818f2e96] [Medline: 19234404]

14. Richiardi L, Baussano I, Vizzini L, Douwes J, Pearce N, Merletti F. Feasibility of recruiting a birth cohort through the internet: the experience of the NINFEA cohort. Eur J Epidemiol 2007;22(12):831-837. [doi: 10.1007/s10654-007-9194-2] [Medline: 17955333]

15. Progetto NINFEA. NINFEA project. Turin, Italy: Azienda Ospedaliero-Universitaria, Citta della Salute e della Scienza di Torino; 2018. URL: https://www.progettoninfea.it/index_en [accessed 2018-11-05] [WebCite Cache ID 73i3f4rVu]

16. The PHP Group. PHP. 2015. URL: http://php.net/ [accessed 2015-05-14] [WebCite Cache ID 6YWJTpCvt]

17. Ruby Community. Ruby is.... 2018. URL: http://www.ruby-lang.org [accessed 2018-05-08] [WebCite Cache ID 6zGfJEOHB]

18. Richiardi L, Pivetta E, Merletti F. Recruiting study participants through Facebook. Epidemiology 2012 Jan;23(1):175. [doi: 10.1097/EDE.0b013e31823b5ee4] [Medline: 22157313]

19. Seaman SR, White IR. Review of inverse probability weighting for dealing with missing data. Stat Methods Med Res 2013 Jun;22(3):278-295. [doi: 10.1177/0962280210395740] [Medline: 21220355]

20. Ekman A, Klint A, Dickman PW, Adami H, Litton J. Optimizing the design of web-based questionnaires--experience from a population-based study among 50,000 women. Eur J Epidemiol 2007;22(5):293-300. [doi: 10.1007/s10654-006-9091-0] [Medline: 17206467]

21. Sullivan PS, Khosropour CM, Luisi N, Amsden M, Coggia T, Wingood GM, et al. Bias in online recruitment and retention of racial and ethnic minority men who have sex with men. J Med Internet Res 2011;13(2):e38 [FREE Full text] [doi: 10.2196/jmir.1797] [Medline: 21571632]

22. Stenhammar C, Bokström P, Edlund B, Sarkadi A. Using different approaches to conducting postal questionnaires affected response rates and cost-efficiency. J Clin Epidemiol 2011 Oct;64(10):1137-1143. [doi: 10.1016/j.jclinepi.2011.01.006] [Medline: 21524566]

23. Lane TS, Armin J, Gordon JS. Online recruitment methods for web-based and mobile health studies: a review of the literature. J Med Internet Res 2015;17(7):e183 [FREE Full text] [doi: 10.2196/jmir.4359] [Medline: 26202991]

24. Heffner JL, Wyszynski CM, Comstock B, Mercer LD, Bricker J. Overcoming recruitment challenges of web-based interventions for tobacco use: the case of web-based acceptance and commitment therapy for smoking cessation. Addict Behav 2013 Oct;38(10):2473-2476 [FRE Full text] [doi: 10.1016/j.addbeh.2013.05.004] [Medline: 23770645]

25. Romano MF, Sardella MV, Alboni F. Web health monitoring survey: a new approach to enhance the effectiveness of telemedicine systems. JMIR Res Protoc 2016 Jun 06;5(2):e101 [FREE Full text] [doi: 10.2196/resprot.5187] [Medline: $\underline{27268949}]$

26. Messer BL, Edwards ML, Dillman DA. Determinants of item nonresponse to web and mail respondents in three address-based mixed-mode surveys of the general public. Surv Pract 2012 Apr 01;5(2):1-9. [doi: 10.29115/SP-2012-0012]

27. de Leeuw E. Reducing missing data in surveys: an overview of methods. Qual Quant 2001 May;35(2):147-160. [doi: 10.1023/A:1010395805406]

28. Yan T, Curtin R. The relation between unit nonresponse and item nonresponse: a response continuum perspective. Int J Public Opin Res 2010 Oct 25;22(4):535-551. [doi: 10.1093/ijpor/edq037]

29. Smyth JD. Comparing check-all and forced-choice question formats in web surveys. Public Opin Q 2006 Mar 01;70(1):66-77. [doi: 10.1093/poq/nfj007]

30. Denscombe M. Item non - response rates: a comparison of online and paper questionnaires. Int J Soc Res Methodol 2009 Oct;12(4):281-291. [doi: 10.1080/13645570802054706]

31. Bethlehem J, Biffignandi S. Handbook of Web Surveys. Hoboken, NJ: John Wiley \& Sons; 2011.

32. Liu M, Cernat A. Item-by-item versus matrix questions. Soc Sci Comput Rev 2016 Nov 30. [doi: 10.1177/0894439316674459]

33. Couper MP, Tourangeau R, Conrad FG, Zhang C. The design of grids in web surveys. Soc Sci Comput Rev 2013 Jun;31(3):322-345 [ㅌRE Full text] [doi: 10.1177/0894439312469865] [Medline: 25258472] 
34. Jones MK, Calzavara L, Allman D, Worthington CA, Tyndall M, Iveniuk J. A comparison of web and telephone responses from a national HIV and AIDS survey. JMIR Public Health Surveill 2016 Jul 29;2(2):e37 [FREE Full text] [doi: 10.2196/publichealth.5184] [Medline: 27473597]

35. Muñoz-Leiva F, Sánchez-Fernández J, Montoro-Ríos F, Ibáñez-Zapata JÁ. Improving the response rate and quality in Web-based surveys through the personalization and frequency of reminder mailings. Qual Quant 2009 Jun 6;44(5):1037-1052. [doi: 10.1007/s11135-009-9256-5]

36. Short CE, Rebar AL, Vandelanotte C. Do personalised e-mail invitations increase the response rates of breast cancer survivors invited to participate in a web-based behaviour change intervention? A quasi-randomised 2-arm controlled trial. BMC Med Res Methodol 2015 Aug 19;15:66 [FREE Full text] [doi: 10.1186/s12874-015-0063-5] [Medline: 26286486]

37. Van Mol C. Improving web survey efficiency: the impact of an extra reminder and reminder content on web survey response. Int J Soc Res Methodol 2016 May 17;20(4):317-327. [doi: 10.1080/13645579.2016.1185255]

38. Dokkum NFB, Koekenbier RH, van den Broek IV, van Bergen JE, Brouwers EE, Fennema JS, et al. Keeping participants on board: increasing uptake by automated respondent reminders in an internet-based Chlamydia screening in the Netherlands. BMC Public Health 2012;12:176 [FREE Full text] [doi: 10.1186/1471-2458-12-176] [Medline: 22404911]

39. Singer E, Ye C. The use and effects of incentives in surveys. Ann Am Acad Polit Soc Sci 2012 Nov 26;645(1):112-141. [doi: 10.1177/0002716212458082]

40. Olsen F, Abelsen B, Olsen JA. Improving response rate and quality of survey data with a scratch lottery ticket incentive. BMC Med Res Methodol 2012 Apr 19;12:52 [FREE Full text] [doi: 10.1186/1471-2288-12-52] [Medline: 22515335]

41. Sardi L, Idri A, Fernández-Alemán JL. A systematic review of gamification in e-Health. J Biomed Inform 2017 Dec;71:31-48. [doi: 10.1016/j.jbi.2017.05.011] [Medline: 28536062]

\title{
Abbreviations \\ IPW: inverse probability weighting \\ NINFEA: Nascita e Infanzia: gli Effetti dell'Ambiente \\ OR: odds ratio
}

\author{
Edited by G Eysenbach; submitted 14.05.18; peer-reviewed by JM Carrillo de Gea, V Andreeva; comments to author 05.07.18; revised \\ version received 22.08.18; accepted 25.08.18; published 07.12.18 \\ Please cite as: \\ Blumenberg C, Zugna D, Popovic M, Pizzi C, Barros AJD, Richiardi L \\ Questionnaire Breakoff and Item Nonresponse in Web-Based Questionnaires: Multilevel Analysis of Person-Level and Item Design \\ Factors in a Birth Cohort \\ J Med Internet Res 2018;20(12):e11046 \\ URL: https://www.jmir.org/2018/12/e11046/ \\ doi: $10.2196 / 11046$ \\ PMID: 30530454
}

(C)Cauane Blumenberg, Daniela Zugna, Maja Popovic, Costanza Pizzi, Aluisio J D Barros, Lorenzo Richiardi. Originally published in the Journal of Medical Internet Research (http://www.jmir.org), 07.12.2018. This is an open-access article distributed under the terms of the Creative Commons Attribution License (https://creativecommons.org/licenses/by/4.0/), which permits unrestricted use, distribution, and reproduction in any medium, provided the original work, first published in the Journal of Medical Internet Research, is properly cited. The complete bibliographic information, a link to the original publication on http://www.jmir.org/, as well as this copyright and license information must be included. 